\title{
Absence of Detectable HIV-1 Viremia after Treatment Cessation in an Infant
}

\author{
Deborah Persaud, M.D., Hannah Gay, M.D., Carrie Ziemniak, M.S., Ya Hui Chen, B.A., \\ Michael Piatak, Jr., Ph.D., Tae-Wook Chun, Ph.D., Matthew Strain, M.D., Ph.D., \\ Douglas Richman, M.D., and Katherine Luzuriaga, M.D.
}

\section{S U M MARY}

An infant born to a woman with human immunodeficiency virus type 1 (HIV-1) infection began receiving antiretroviral therapy (ART) 30 hours after birth owing to high-risk exposure. ART was continued when detection of HIV-1 DNA and RNA on repeat testing met the standard diagnostic criteria for infection. After therapy was discontinued (when the child was 18 months of age), levels of plasma HIV-1 RNA, proviral DNA in peripheral-blood mononuclear cells, and HIV-1 antibodies, as assessed by means of clinical assays, remained undetectable in the child through 30 months of age. This case suggests that very early ART in infants may alter the establishment and long-term persistence of HIV-1 infection.

From the Department of Pediatrics, Johns Hopkins University School of Medicine, Baltimore (D.P., C.Z., Y.H.C.), Frederick National Laboratory for Cancer Research, Leidos Biomedical Research, Frederick (M.P.), and the Laboratory of Immunoregulation, National Institute of Allergy and Infectious Diseases, National Institutes of Health, Bethesda (T.-W.C.) — all in Maryland; the Department of Pediatrics, University of Mississippi Medical Center, Jackson (H.G.); the University of California San Diego, La Jolla, and the Veterans Affairs San Diego Healthcare System, San Diego (M.S., D.R.); and the Department of Pediatrics, Program in Molecular Medicine, and Center for Clinical and Translational Science, University of Massachusetts Medical School, Worcester (K.L.). Address reprint requests to Dr. Persaud at Johns Hopkins University School of Medicine, 720 Rutland Ave., Ross Bldg., Rm. 1170, Baltimore, MD 21287, or at dpers@jhmi.edu.

This article was published on October 23, 2013, at NEJM.org.

N Engl J Med 2013;369:1828-35. DOI: 10.1056/NEJMoa1302976

Copyright (c) 2013 Massachusetts Medical Society.
$\mathrm{N}$ EARLY 70 MILLION PERSONS HAVE ACQUIRED HIV-1 INFECTION SINCE the epidemic was recognized, ${ }^{1}$ but a "cure" has been documented in one person, known as "the Berlin Patient." 2,3 A cure for HIV-1 infection occurred in this person after he underwent treatment for acute myelogenous leukemia with total ablative chemotherapy, radiation therapy, and stem-cell transplantation with donor cells homozygous for chemokine receptor 5 (CCR5) delta32, with associated graft-versus-host disease. The case of the Berlin Patient shows that longlived, replication-competent HIV-1 reservoirs can be reduced or cleared sufficiently to permit the discontinuation of ART without subsequent viral rebound. We report data from a 30-month-old child who had met the standard diagnostic criteria for HIV-1 infection and who now has undetectable levels of circulating HIV-1 RNA, proviral DNA, and HIV-1 antibodies, as assessed by means of clinical assays, after combination ART was administered between 30 hours and 18 months of age.

\section{CASE REPORT}

An infant was born by spontaneous vaginal delivery at 35 weeks of gestation to a woman who had received no prenatal care. Rapid HIV-1 testing in the mother was positive during labor. Delivery occurred before antiretroviral prophylaxis was administered. Maternal HIV-1 infection was confirmed by means of Western blot testing. The mother's plasma viral load, CD4+ T-cell count, and HIV-1 subtype and genotype are summarized in Table 1.

ART was initiated in the infant at 30 hours of age. A three-drug regimen of zidovudine (at a dose of $2 \mathrm{mg}$ per kilogram of body weight every 6 hours), lamivudine (at a dose of $4 \mathrm{mg}$ per kilogram twice daily), and nevirapine (at a dose of $2 \mathrm{mg}$ per kilogram twice daily) was selected to provide prophylaxis for high-risk 


\begin{tabular}{|c|c|c|}
\hline Test & Result & Antiretroviral Therapy \\
\hline \multicolumn{3}{|l|}{ Mother } \\
\hline Rapid HIV antibody, at delivery & Positive & None \\
\hline $\begin{array}{l}\text { HIV ELISA and confirmatory Western } \\
\text { blot, at } 24 \mathrm{hr}\end{array}$ & Positive & None \\
\hline Viral load, at $24 \mathrm{hr}$ & 2423 copies/ml & None \\
\hline CD4+ T-cell count, at 14 days & 644 cells $/ \mathrm{mm}^{3}$ & None \\
\hline HIV-I genotype and subtype, at 14 days & Wild-type, subtype B & None \\
\hline CD4+ T-cell count, at 26 mo & 513 cells $/ \mathrm{mm}^{3}$ & None \\
\hline HIV-1 viral load, at 26 mo & 6763 copies/ml & None \\
\hline HLA typing, at $26 \mathrm{mo}$ & $\mathrm{A} 3, \mathrm{~A} 23, \mathrm{~B} 7, \mathrm{~B} 14, \mathrm{Cw} 7$, and $\mathrm{Cw8}$ & None \\
\hline $\begin{array}{l}\text { Mutation status in CCR5 delta32, } \\
\text { at } 26 \text { mo }\end{array}$ & Nonmutated & None \\
\hline Frequency of infected cells, at $28 \mathrm{mo}$ & 137 IUPM & None \\
\hline \multicolumn{3}{|l|}{ Child } \\
\hline HIV-1 DNA, at $30 \mathrm{hr}$ & Positive & Zidovudine \\
\hline HIV-l RNA, at $31 \mathrm{hr}$ & 19,812 copies $/ \mathrm{ml}$ & Zidovudine, lamivudine, and nevirapine \\
\hline HIV-1 RNA, at 6 days & 2617 copies $/ \mathrm{ml}$ & Zidovudine, lamivudine, and nevirapine \\
\hline HIV-1 RNA, at 11 days & 516 copies $/ \mathrm{ml}$ & $\begin{array}{l}\text { Zidovudine, lamivudine, and ritonavir- } \\
\text { boosted lopinavir }\end{array}$ \\
\hline HIV-1 RNA, at 19 days & 265 copies/ml & $\begin{array}{l}\text { Zidovudine, lamivudine, and ritonavir- } \\
\text { boosted lopinavir }\end{array}$ \\
\hline HIV-I RNA, at 29 days & $<48$ copies $/ \mathrm{ml}$ & $\begin{array}{l}\text { Zidovudine, lamivudine, and ritonavir- } \\
\text { boosted lopinavir }\end{array}$ \\
\hline CD4+ T-cell percentage, at 8 days & $69 \%$ & $\begin{array}{l}\text { Zidovudine, lamivudine, and ritonavir- } \\
\text { boosted lopinavir }\end{array}$ \\
\hline HLA typing, at $26 \mathrm{mo}$ & $\mathrm{A} 3, \mathrm{~A} 68, \mathrm{~B} 7, \mathrm{~B} 39$, and $\mathrm{Cw} 7$ & None \\
\hline $\begin{array}{l}\text { Mutation status in CCR5 delta32, } \\
\text { at } 26 \text { mo }\end{array}$ & Nonmutated & None \\
\hline
\end{tabular}

* All specified time points are post partum. CCR5 denotes chemokine receptor 5 gene, ELISA enzyme-linked immunosorbent assay, HIV human immunodeficiency virus, HIV-1 HIV type 1, and IUPM infectious units per 1 million resting CD4+ T cells.

HIV-1 exposure and to minimize the likelihood of generating resistant viral variants in the event that the infant had been infected in utero.

The detection of HIV-1 DNA in peripheralblood mononuclear cells (PBMCs) in blood obtained at 30 hours of age (Table 1 ) and the detection of HIV-1 RNA (19,812 copies per milliliter) in a separate blood sample collected at 31 hours of age met the standard diagnostic criteria for HIV-1 infection in the infant. ${ }^{4}$ Therefore, ART was continued. When the infant was 1 week of age, ritonavir-boosted lopinavir was substituted for nevirapine to reduce the risk of antiretroviral drug resistance in case there was incomplete adherence to the prescribed ART. The decision to implement this regimen preceded warnings from the Food and Drug Administration against the use of ritonavir-boosted lopinavir in infants younger than 14 days of age. ${ }^{5}$

While the infant was receiving ART, the HIV1 RNA level remained detectable in plasma at three additional time points (2617 copies per milliliter at 6 days of age, 516 copies per milliliter at 11 days of age, and 265 copies per milliliter at 19 days of age) (Table 1 and Fig. 1) before declining below assay-detection limits when the infant was 29 days of age. The decline in the plasma viral load was biphasic and similar to 


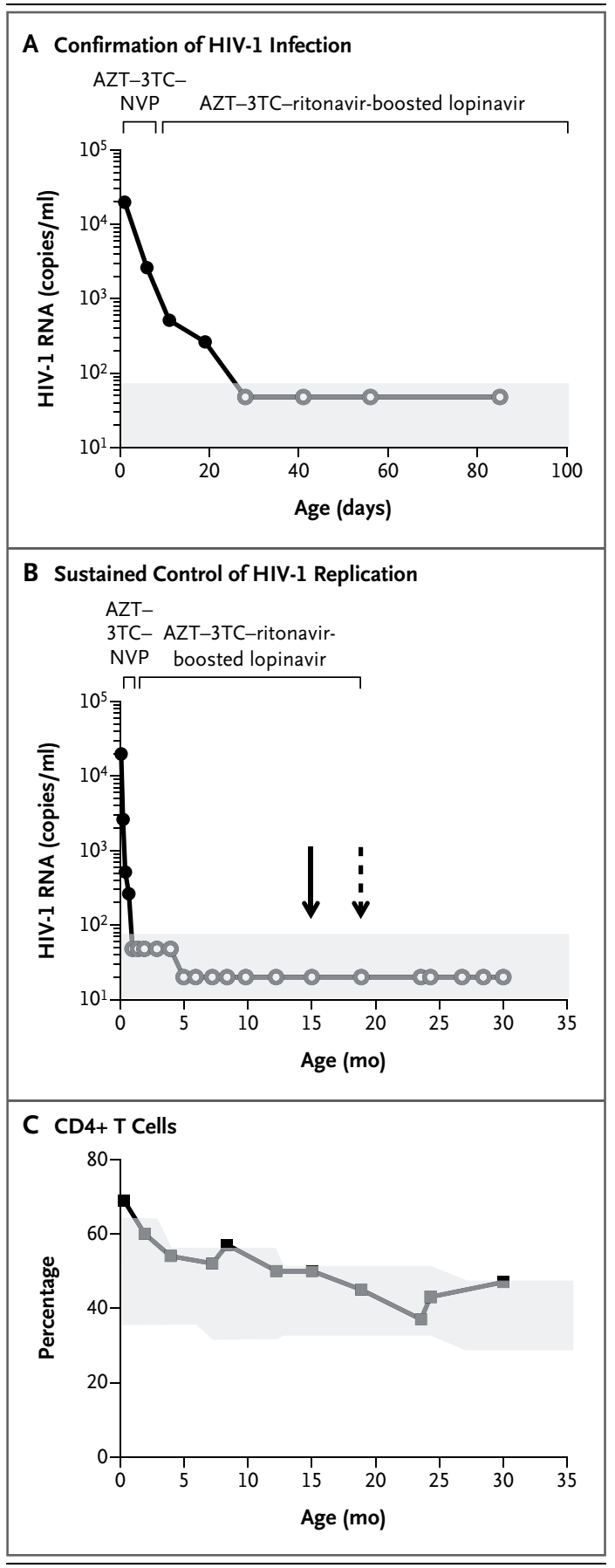

that described previously in HIV-1 infected infants $^{7,8}$ and adults receiving ART. ${ }^{9}$

In the infant's first year of life, during which the infant was not breast-fed, adherence to ART was assessed as adequate on the basis of pharmacy records indicating timely prescription refills, undetectable plasma viral loads, and redcell macrocytosis during zidovudine treatment.
Figure 1. Detection of Human Immunodeficiency Virus Type 1 (HIV-1) Infection in the Child.

Panel A shows HIV-1 RNA levels indicating confirmed HIV-l infection, with positive values for HIV-l RNA in plasma at four time points before and after the initiation of antiretroviral therapy (ART). The decline in the viral load was biphasic, which is typically seen during effective ART. Panel B shows HIV-1 RNA levels indicating sustained control of HIV-1 replication during ART and after the discontinuation of therapy. The solid arrow indicates the last time that prescriptions for ART were filled (at 15 months of age, according to pharmacy records), and the dashed arrow the time of the last administration of ART (at 18 months of age, according to maternal report). In both Panel A and Panel B, solid circles indicate detectable HIV-1 RNA, and open circles undetectable HIV-I RNA; the shaded area indicates the limit of detection of the plasma viral-load assay. Panel $C$ shows the percentage of CD4+ T cells from the child's birth until 30 months of age. The shaded area indicates the CD4+ T-cell percentage in the normal range (10th to 90 th percentiles); fluctuations in the normal range are due to age-related changes. ${ }^{6}$ 3TC denotes lamivudine, AZT zidovudine, and NVP nevirapine.

Concern about medication adherence was raised when the child was 18 months of age, when the red-cell mean corpuscular volume, which had been more than 101 femtoliters (fl) before 15 months of age, decreased to $95 \mathrm{fl}$, although the plasma level of HIV-1 RNA remained undetectable $(<20$ copies per milliliter).

Between 18 and 23 months of age, the child missed several clinic visits. When the child was brought back for care at 23 months of age, the mother reported that ART had been discontinued when the child was 18 months of age, although pharmacy records indicated that the prescription was last refilled when the child was 15 months of age. In blood samples obtained at 23 and 24 months of age, the plasma level of HIV-1 RNA was undetectable. A repeat HIV-1 DNA polymerase-chain-reaction (PCR) test at 24 months of age was negative, as was an HIV-1 antibody test.

At the time of this report, the child had not received any antiretroviral drugs through 30 months of age, and the plasma level of HIV-1 RNA had remained undetectable by routine clinical assays (Fig. 1). Circulating HIV-1 antibodies have also not been detected (Fig. S1 in the Supplementary Appendix, available with the full text of this article at NEJM.org). The CD4+ T-cell percentages were within or exceeded the 
normal range for age at all time points tested (Fig. 1C). ${ }^{6}$ Growth and development have been normal. Detailed virologic and immunologic studies were performed to characterize the persistence of HIV-1 infection in this unique case.

METHODS

DIAGNOSIS AND MONITORING OF HIV-I INFECTION

We performed standard HIV-1 DNA PCR testing with the use of the Amplicor HIV-1 DNA assay (Roche Molecular Systems) and HIV-1 RNA testing with the use of the COBAS AmpliPrep/COBAS Taqman HIV-1 test (Roche Molecular Systems). The testing was performed at laboratories that were certified by the Clinical Laboratory Improvement Amendments (CLIA) program: Focus Diagnostics and Mayo Medical Laboratories for HIV-1 DNA testing and University of Mississippi Medical Center for HIV-1 RNA testing. The COBAS AmpliPrep/COBAS Taqman HIV-1 test, version 1.0 (limit of detection [LOD], $<48$ copies per milliliter), was used for samples tested before the child was 5 months of age, and version 2.0 (LOD, $<20$ copies per milliliter) was used thereafter. $\mathrm{CD} 4+\mathrm{T}$ cells were enumerated with the use of flow cytometry.

HIV-1-SPECIFIC IMMUNE RESPONSES, HLA TYPING, AND CCR 5 GENOTYPING

HIV-1 antibody testing was performed with the use of enzyme-linked immunosorbent assays and Western blot testing (Cambridge Biotech HIV-1 Western Blot Kit, Maxim Biomedical). Intracellular cytokine assays were used to detect HIV-1-specific CD4+ and CD8+ T-cell responses to pooled gag and nef peptides. Cell-surface markers for immune activation were evaluated with the use of flow cytometry. HLA typing was performed with the use of the Bio-Rad HLA Sequence Specific Primers kit (Biotest). CCR5 genotyping for the delta32 mutation was performed with the use of previously published methods. ${ }^{10}$

\section{VIROLOGIC ASSAYS TO QUANTIFY HIV-I PERSISTENCE}

The presence of replication-competent virus in maternal and infant samples was determined with the use of a limiting-dilution quantitative coculture assay of PBMCs enriched for resting CD4+ T cells. ${ }^{11}$ Replication efficiencies of the maternal isolates were compared with an HIV-1 reference strain to assess viral fitness. ${ }^{12}$ Lowlevel viremia was quantified by means of two assays: a single-copy viral-load assay ${ }^{13}$ and a modified COBAS AmpliPrep/COBAS Taqman HIV-1 test, version 2.0. ${ }^{14}$ We tested for the presence of proviral DNA and 2-long terminal repeat circles in PBMCs, resting CD4+ T cells, and cellular fractions enriched for monocytes and activated cells with the use of a highly sensitive droplet digital PCR assay (LOD, $<3$ copies per $10^{6}$ cells). ${ }^{15}$

\section{RESULTS}

IMMUNOLOGIC AND VIROLOGIC TESTING

Maternal HIV-1 antibody tests that were performed 24 months after delivery showed reactivity to all nine HIV-1 proteins tested (Fig. S1 in the Supplementary Appendix). The mother did not begin receiving ART. At 26 months after delivery, the maternal HIV-1 RNA level was 6763 copies per milliliter. At 28 months after delivery, fully replication-competent virus was recovered from a maternal blood sample at a frequency of 137 infectious units per million resting CD4+ T cells; viral isolates showed replication kinetics similar to the IIIB laboratory strain of HIV-1. HLA typing of the mother and infant revealed shared haplotypes, confirming their relationship (Table 1). Neither the mother nor the infant had HLA class I alleles that are associated with spontaneous control of HIV-1 infection (HLA-B27 or HLA$B \star 57)$; both were nonmutated for CCR 5 .

HIV-1 antibodies were not detected in the child at 24, 26, and 28 months of age (Fig. S1 in the Supplementary Appendix). T-cell activation markers were within normal limits at 24 and 30 months of age (at 24 months, $2 \%$ of the $\mathrm{T}$ cells were CD4+/HLA-DR+; at 30 months, $6 \%$ of the T cells were CD8+/CD38+/HLA-DR+). HIV-1-specific $\mathrm{CD} 4+$ and $\mathrm{CD} 8+\mathrm{T}$-cell responses were not detected at 28 months of age.

Ultrasensitive virologic tests were performed to evaluate the persistence of HIV-1 infection in the child (Table 2). Viral RNA was detected at a single-copy level in plasma obtained at 24 months of age but was not detected at 26 months of age. HIV-1 proviral DNA was detected near the limits of detection at both time points but not in resting CD4+ T cells (Table 2). A culture of 22 million resting CD4+ T cells obtained at 24 months of age, during a period in which the child was not receiving ART, did not yield replication-competent HIV-1. 


\begin{tabular}{|c|c|c|c|}
\hline \multirow[t]{2}{*}{ Sample Type } & \multirow[t]{2}{*}{ Quantity } & \multicolumn{2}{|c|}{ Cells Tested } \\
\hline & & $\begin{array}{l}\text { no. of cells or } \\
\text { plasma volume }\end{array}$ & $\begin{array}{c}\text { no. of positive } \\
\text { replicates/ } \\
\text { no. of wells }\end{array}$ \\
\hline \multicolumn{4}{|l|}{ Total proviral DNA } \\
\hline \multicolumn{4}{|l|}{ PBMCs } \\
\hline At $24 \mathrm{mo}$ & $<2.7$ copies $/ 10^{6}$ cells & 122,000 & $0 / 2$ \\
\hline At $26 \mathrm{mo}$ & 4.2 copies $/ 10^{6}$ cells & 113,000 & $1 / 6$ \\
\hline \multicolumn{4}{|l|}{ Resting CD4+ T cells } \\
\hline At 24 mo & $<3.5$ copies $/ 10^{6}$ cells & 96,500 & $0 / 3$ \\
\hline At $26 \mathrm{mo}$ & $<2.5$ copies $/ 10^{6}$ cells & 134,000 & $0 / 6$ \\
\hline \multicolumn{4}{|c|}{ PBMCs enriched for activated CD4+ T cells } \\
\hline At $24 \mathrm{mo}$ & $<2.2$ copies $/ 10^{6}$ cells & 154,000 & $0 / 6$ \\
\hline At $26 \mathrm{mo}$ & $<2.6$ copies $/ 10^{6}$ cells & 130,000 & $0 / 6$ \\
\hline \multicolumn{4}{|l|}{ Monocyte-derived adherent cells } \\
\hline At 24 mo & 37.6 copies $/ 10^{6}$ cellst & 14,300 & $1 / 3$ \\
\hline At $26 \mathrm{mo}$ & $<11.5$ copies $/ 10^{6}$ cells & 29,000 & $0 / 6$ \\
\hline \multicolumn{4}{|l|}{ Residual viremia in plasma } \\
\hline At 24 mo & 1 copy/ml & $4 \mathrm{ml}$ & $3 / 3$ \\
\hline At $26 \mathrm{mo}$ & $<2$ copies $/ \mathrm{ml}$ & $4 \mathrm{ml}$ & $0 / 4$ \\
\hline Infectious virus recovery at 24 mo & $<0.05$ IUPM & $\begin{array}{l}22 \times 10^{6} \text { resting } \\
\text { CD } 4+T \text { cells }\end{array}$ & $0 / 22$ \\
\hline
\end{tabular}

\section{DISCUSSION}

We report data from a 30-month-old child who met the standard diagnostic criteria for HIV-1 infection, received combination ART between 30 hours and 18 months of age, and subsequently had controlled HIV-1 viremia for 12 months while not receiving ART. The absence of rebound viremia, the undetectable replication-competent virus, the almost-complete disappearance of cellassociated HIV-1 DNA, and the absence of HIV-1specific immune responses while the child was not receiving ART suggest that replication-competent HIV-1 reservoirs may not have been established or were markedly abated, if not extinguished. ${ }^{16}$

Rare cases of transient HIV infection in infants have been reported, on the basis of intermittent detection of HIV-1 p24 antigen or DNA in peripheral blood. ${ }^{17-20}$ One cohort study showed that $6.4 \%$ of 188 infants had one or more positive tests for HIV that were followed by negative tests. ${ }^{20}$ However, forensic and phylogenetic studies could not rule out laboratory contamination or sample mislabeling in reported cases of spontaneous HIV-1 clearance. ${ }^{21}$ In the present case report, the five positive tests indicating HIV-1 infection were performed in CLIA-certified laboratories with the use of separate blood specimens and standard clinical-assay protocols. Under this scenario, repeated sample mix-up or contamination was unlikely. Unfortunately, clinical specimens are not routinely saved, which precluded further assessment of specimens from those time points.

The current standard definition of HIV-1 infection in an infant requires the detection of HIV-1 nucleic acids in at least two separate clinical samples. ${ }^{4}$ An infant in whom HIV-1 DNA is detected in blood obtained within the first 48 hours after birth is considered to have acquired the infection in utero. ${ }^{22}$ The detection of HIV-1 proviral DNA in this infant's peripheral blood at 
30 hours of age, along with a plasma viral load of 19,812 copies per milliliter detected at 31 hours of age, is consistent with in utero infection. In two separate studies, the median viral loads at birth in infants who had been infected in utero were 10,800 copies per milliliter ${ }^{23}$ and 26,940 copies per milliliter, ${ }^{24}$ as compared with undetectable levels in infants who were infected peripartum.

We believe that infection with replicating virus was likely, given the sequential detection of RNA in three serial blood samples obtained during the first few weeks of life while the infant was receiving combination ART with reversetranscriptase inhibitors. The biphasic decline in viremia after the initiation of ART, with the rapid clearance (steep decline) of short-lived virus-producing cells (e.g., activated CD4+ T cells), followed by a slower decline, is consistent with the inhibition of active infection rather than with the clearance of passively transferred HIV1-infected maternal cells without infection of the infant's cells. With these findings, the infant met the standard diagnostic criteria for HIV-1 infection (most likely acquired in utero) as well as the criteria for initiation of ART and for participation in clinical trials sponsored by the National Institutes of Health. ${ }^{22-25}$

We evaluated whether maternal-fetal blood transfusion could account for the detection of HIV-1 nucleic acid in the infant. An initial plasma viral load of approximately 20,000 copies per milliliter in a $2.5 \mathrm{~kg}$ neonate is equivalent to a total body count of 5 million HIV-1 RNA copies or approximately 2.5 million virions. Such a result would have required the transfer of approximately 2 liters of maternal blood into this infant (whose total blood volume is only $250 \mathrm{ml}$ ). Likewise, the possibility that persistent detection of HIV-1 RNA during the first 3 weeks of life represented the passive transfer of virions from maternal blood is not consistent with the earlyinfection events associated with postexposure prophylaxis in maternal-fetal transmission or neonatal HIV-1 infection, considering that the half-life of virions is 1 to 2 hours at most. Thus, the repeated detection of HIV-1 RNA in plasma through the infant's first 19 days of life, while the infant was receiving ART, shows that there were virus-producing cells in the infant.

It is also conceivable that maternal microchimerism could have resulted in the detection of HIV-1 nucleic acid in the infant. Microchimerism has been detected in infants born to HIV-positive women but has not been associated with an increased risk of HIV-1 transmission. ${ }^{26}$ Although we were not able to directly assess maternal cells in the infant's circulation, transfused maternal cells at the levels reported previously ( 0.3 to $0.6 \%$ of neonatal cells ${ }^{26}$ ) are not likely to have resulted in the levels of plasma HIV-1 RNA that were detected shortly after birth in this infant.

A curious finding in this infant is the persistence of traces of HIV-1 nucleic acid. The traces of viral nucleic acid may represent the persistence of replication-defective genomes or false positive signals at the threshold of detection of the assays, as was recently reported for the Berlin Patient. ${ }^{27}$ Attempts to amplify HIV-1 from infant samples obtained for viral sequencing at 24 and 26 months of age were unsuccessful, as were efforts to locate the screening samples obtained when the infant was a newborn to perform viral sequencing. The latter situation also precluded linkage analysis to maternal viral variants, which represents a limitation of this case report.

ART that is initiated between 1 and 3 months of age has been shown to modify HIV-1 persistence in that infants who receive early treatment are often HIV-1 seronegative and do not have circulating viremia while they are receiving ART, but viral rebound has been observed when ART is discontinued. ${ }^{28-30}$ Approximately 5 to $10 \%$ of adults who receive early ART have sustained control of HIV-1 replication after the discontinuation of therapy, although evidence for ongoing HIV-1 infection remains. ${ }^{31,32}$ The current case differs from those described in children ${ }^{29}$ and adults $^{32}$ who receive early treatment in that circulating proviral HIV-1 DNA and plasma HIV-1 RNA were only intermittently detected at levels just above the limits of detection of the assays, replication-competent virus could not be recovered, and the child remains HIV-1 seronegative even though ART was discontinued. This situation closely mimics the virologic and immunologic biomarkers of the Berlin Patient at 5 years of follow-up. ${ }^{27}$

Viral and host factors could have contributed to the reported outcome in this child. The maternal HIV-1 RNA levels were relatively low at delivery, although fully replication-competent virus, with replication kinetics that were similar to a laboratory strain, was readily cultured from maternal cells 26 months post partum, from a blood sample showing a plasma viral load of 
nearly 7000 copies per milliliter (Fig. S2 in the Supplementary Appendix). Although neither the mother nor the infant had HLA class I alleles that have been associated with control of HIV-1 infection, ${ }^{33}$ it is possible that strong maternal immune responses or other unknown host factors were responsible for the relatively low viral load seen in the mother, although maternal samples were not available for additional testing. The child remains in care, and at the age of 36 months, at least 18 months after the cessation of ART, the child has no detectable level of HIV-1 RNA.

This case suggests that very early ART may interfere with either the quantities or qualities of persistent reservoirs of replication-competent virus. Antiretroviral prophylaxis is routinely recommended for infants who have been exposed to HIV-1, with multidrug regimens recommended in high-risk cases. Furthermore, the initiation of ART in infected infants markedly reduces HIVrelated mortality among infants ${ }^{25}$ and is recommended by the World Health Organization. This global standard may facilitate planned proof-ofconcept studies of very early ART to modify persistent HIV-1 infection in infants, with an aim toward sparing them a lifetime of therapy.
The views expressed in this article are those of the authors and do not necessarily reflect the official views of the National Institute of Allergy and Infectious Diseases (NIAID), the National Institutes of Health (NIH), or the Department of Health and Human Services, nor does the mention of trade names, commercial products, or organizations imply endorsement by the U.S. government.

Supported by grants from the NIH (AI93701 and HD0577849, to Dr. Persaud), by funding from the American Foundation for AIDS Research (to Drs. Persaud and Luzuriaga); by grants from the International Maternal Pediatric Adolescent AIDS Clinical Trials Network (U01-AI-068632 and UM1-AI-068632, to Drs. Persaud and Luzuriaga), the University of Massachusetts Center for Clinical and Translational Science (UL1TR000161, to Dr. Luzuriaga), and the Collaboratory of AIDS Researchers for Eradication (AI080193, AI69432, AI047745, AI74621, AI306214, and AI096113); and by funding from the Department of Veterans Affairs (to Drs. Strain and Richman). The research was also supported in part by grants from the Johns Hopkins University Center for AIDS Research (CFAR) (P30-AI094189) and the University of Massachusetts Medical School CFAR (P30-AI042845) and by the NIAID Intramural Research Program. Specific specialty viral-load testing was funded by a contract from the National Cancer Institute (HHSN261200800001E).

Disclosure forms provided by the authors are available with the full text of this article at NEJM.org.

We thank the family of the child discussed in this article, who agreed to the presentation of this case in order to advance medical knowledge; Linda Lambrecht, Joyce Pepe, Robin Brody, Steven Lada, and Steffney Rought for technical support; Margaret McManus for assistance with data analysis; Joel Blankson for technical advice; Mindy Donovan for preparation of an earlier version of the manuscript; and the staff at Stemcyte for chemokine receptor 5 gene (CCR5) genotyping.

REFERENCES

1. UNAIDS World AIDS Day global report 2012 (http://www.unaids.org/en/resources/ campaigns/20121120_globalreport2012). 2. Hütter $\mathrm{G}$, Nowak D, Mossner M, et al. Long-term control of HIV by CCR5 Delta32/ Delta32 stem-cell transplantation. $\mathrm{N}$ Engl J Med 2009;360:692-8.

3. Allers $\mathrm{K}$, Hütter $\mathrm{G}$, Hofmann J, et al. Evidence for the cure of HIV infection by CCR5 Delta32/Delta32 stem cell transplantation. Blood 2011;117:2791-9.

4. Panel on Antiretroviral Therapy and Medical Management of HIV-Infected Children. Guidelines for the use of antiretroviral agents in pediatric HIV infection. Rockville, MD: AIDSinfo, 2012 (http:/l aidsinfo.nih.gov/guidelines/html/2/ pediatric-treatment-guidelines/0).

5. FDA Drug Safety Communication. Serious health problems seen in premature babies given Kaletra (lopinavir/ritonavir) oral solution. Silver Spring, MD: Food and Drug Administration, 2011 (http://www.fda .gov/Drugs/DrugSafety/ucm246002.htm). 6. Shearer WT, Rosenblatt HM, Gelman RS, et al. Lymphocyte subsets in healthy children from birth through 18 years of age: the Pediatric AIDS Clinical Trials Group P1009 study. J Allergy Clin Immunol 2003;112:973-80.

7. Luzuriaga $\mathrm{K}$, Wu H, McManus $\mathrm{M}$, et al. Dynamics of human immunodeficiency virus type 1 replication in vertically infected infants. J Virol 1999;73:362-7.

8. Palumbo $\mathrm{P}, \mathrm{Wu} \mathrm{H}$, Chadwick E, et al Virologic response to potent antiretroviral therapy and modeling of HIV dynamics in early pediatric infection. J Infect Dis 2007;196:23-9.

9. Perelson AS, Neumann AU, Markowitz M, Leonard JM, Ho DD. HIV-1 dynamics in vivo: virion clearance rate, infected cell life-span, and viral generation time. Science 1996;271:1582-6.

10. Petz LD, Redei I, Bryson Y, et al. Hematopoietic cell transplantation with cord blood for cure of HIV infections. Biol Blood Marrow Transplant 2013;19:393-7. 11. Persaud D, Palumbo PE, Ziemniak C et al. Dynamics of the resting CD4(+) T-cell latent HIV reservoir in infants initiating HAART less than 6 months of age. AIDS 2012;26:1483-90.

12. Blankson JN, Bailey JR, Thayil S, et al Isolation and characterization of replication-competent human immunodeficiency virus type 1 from a subset of elite suppressors. J Virol 2007;81:2508-18.

13. Palmer S, Wiegand AP, Maldarelli F, et al. New real-time reverse transcriptaseinitiated PCR assay with single-copy sensitivity for human immunodeficiency virus type 1 RNA in plasma. J Clin Microbiol 2003;41:4531-6.
14. Chun TW, Murray D, Justement JS, et al. Relationship between residual plasma viremia and the size of HIV proviral DNA reservoirs in infected individuals receiving effective antiretroviral therapy. J Infect Dis 2011;204:135-8.

15. Strain MC, Lada SM, Luong T, et al. Highly precise measurement of HIV DNA by droplet digital PCR. PLoS One 2013; 8(4):e55943.

16. Deeks SG, Autran B, Berkhout B, et al. Towards an HIV cure: a global scientific strategy. Nat Rev Immunol 2012;12:607-14. 17. Bakshi SS, Tetali S, Abrams EJ, Paul MO, Pahwa SG. Repeatedly positive human immunodeficiency virus type 1 DNA polymerase chain reaction in human immunodeficiency virus-exposed seroreverting infants. Pediatr Infect Dis J 1995;14:658-62. 18. Bryson YJ, Pang S, Wei LS, Dickover R, Diagne A, Chen IS. Clearance of HIV infection in a perinatally infected infant. N Engl J Med 1995;332:833-8.

19. Newell ML, Dunn D, De Maria A, et al. Detection of virus in vertically exposed HIV-antibody-negative children. Lancet 1996;347:213-5.

20. Roques PA, Gras G, Parnet-Mathieu F, et al. Clearance of HIV infection in 12 perinatally infected children: clinical, virological and immunological data. AIDS 1995; 9(12):F19-F26. 
21. Frenkel LM, Mullins JI, Learn GH, et al. Genetic evaluation of suspected cases of transient HIV-1 infection of infants. Science 1998;280:1073-7.

22. Bryson YJ, Luzuriaga K, Sullivan JL, Wara DW. Proposed definitions for in utero versus intrapartum transmission of HIV-1. N Engl J Med 1992;327:1246-7.

23. Shearer WT, Quinn TC, LaRussa P, et al Viral load and disease progression in infants infected with human immunodeficiency virus type 1. N Engl J Med 1997; 336:1337-42.

24. Dickover RE, Dillon M, Leung KM, et al. Early prognostic indicators in primary perinatal human immunodeficiency virus type 1 infection: importance of viral RNA and the timing of transmission on longterm outcome. J Infect Dis 1998;178:375-87. 25. Violari A, Cotton MF, Gibb DM, et al. Early antiretroviral therapy and mortality among HIV-infected infants. N Engl J Med 2008;359:2233-44.
26. Lee TH, Chafets DM, Biggar RJ, McCune JM, Busch MP. The role of transplacental microtransfusions of maternal lymphocytes in in utero HIV transmission. J Acquir Immune Defic Syndr 2010;55 143-7.

27. Yukl SA, Boritz E, Busch $M$, et al Challenges in detecting HIV persistence during potentially curative interventions: a study of the Berlin Patient. PLoS Pathog 2013;9(5):e1003347.

28. Luzuriaga $\mathrm{K}$, McManus $M$, Catalina $M$, et al. Early therapy of vertical human immunodeficiency virus type 1 (HIV-1) infection: control of viral replication and absence of persistent HIV-1-specific immune responses. J Virol 2000;74:6984 91.

29. Luzuriaga K, McManus $M$, Mofenson L, Britto P, Graham B, Sullivan JL. A trial of three antiretroviral regimens in HIV-1infected children. N Engl J Med 2004;350 2471-80.
30. Persaud D, Ray SC, Kajdas J, et al. Slow human immunodeficiency virus type 1 evolution in viral reservoirs in infants treated with effective antiretroviral therapy. AIDS Res Hum Retroviruses 2007; 23:381-90.

31. Hocqueloux L, Prazuck T, AvettandFenoel V, et al. Long-term immunovirologic control following antiretroviral therapy interruption in patients treated at the time of primary HIV-1 infection. AIDS 2010;24:1598-601.

32. Sáez-Cirión A, Bacchus C, Hocqueloux L, et al. Post-treatment HIV-1 controllers with a long-term virological remission af ter the interruption of early initiated antiretroviral therapy ANRS VISCONTI Study. PLoS Pathog 2013;9(3):e1003211.

33. Fellay J, Shianna KV, Ge D, et al A whole-genome association study of major determinants for host control of HIV-1. Science 2007;317:944-7.

Copyright (c) 2013 Massachusetts Medical Societv. 